\title{
Green Nanocoatings Based on the Deposition of Zirconium Oxide: The Role of the Substrate
}

\author{
Vitor Bonamigo Moreira ${ }^{1,2} \mathbb{D}$, Anna Puiggalí-Jou 1,3, Emilio Jiménez-Piqué ${ }^{3,4}$, Carlos Alemán 1,3,5 $\mathbb{D}$, \\ Alvaro Meneguzzi ${ }^{2}$ (D) and Elaine Armelin $1,3, *$ (D)
}

1 Department of Chemical Engineering, Universitat Politècnica de Catalunya, Campus Diagonal Besòs (EEBE), C/Eduard Maristany, 10-14, Building I, 2nd Floor, 08019 Barcelona, Spain; vitor.moreira@upc.edu (V.B.M.); anna.puiggali@upc.edu (A.P.-J.); carlos.aleman@upc.edu (C.A.)

2 Post-Graduation Program in Mining, Metallurgical and Materials Engineering (PPGE3M), Universidade Federal do Rio Grande do Sul (UFRGS), Av. Bento Gonçalves, 9500-91501-970 Porto Alegre, RS, Brazil; meneguzzi@ufrgs.br

3 Barcelona Research Center for Multiscale Science and Engineering, Universitat Politècnica de Catalunya, Campus Diagonal Besòs (EEBE), C/Eduard Maristany, 10-14, Building I, Basement Floor, 08019 Barcelona, Spain; emilio.jimenez@upc.edu

4 Department of Materials Science and Engineering, Universitat Politècnica de Catalunya, Campus Diagonal Besòs-EEBE, C/Eduard Maristany, 10-14, Building I, 1st Floor, 08019 Barcelona, Spain

5 Institute for Bioengineering of Catalonia (IBEC), The Barcelona Institute of Science and Technology, Baldiri Reixac, 10-12, 08028 Barcelona, Spain

* Correspondence: elaine.armelin@upc.edu; Tel.: +34-934054447

Citation: Bonamigo Moreira, V.; Puiggalí-Jou, A.; Jiménez-Piqué, E.; Alemán, C.; Meneguzzi, A.; Armelin, E. Green Nanocoatings Based on the Deposition of Zirconium Oxide: The Role of the Substrate. Materials 2021, 14, 1043. https://doi.org/10.3390/ ma14041043

Academic Editor: Artur Czupryński

Received: 15 January 2021

Accepted: 17 February 2021

Published: 23 February 2021

Publisher's Note: MDPI stays neutral with regard to jurisdictional claims in published maps and institutional affiliations.

Copyright: (c) 2021 by the authors. Licensee MDPI, Basel, Switzerland. This article is an open access article distributed under the terms and conditions of the Creative Commons Attribution (CC BY) license (https:/ / creativecommons.org/licenses/by/ $4.0 /$ )
Abstract: Herein, the influence of the substrate in the formation of zirconium oxide monolayer, from an aqueous hexafluorozirconic acid solution, by chemical conversion and by electro-assisted deposition, has been approached. The nanoscale dimensions of the $\mathrm{ZrO}_{2}$ film is affected by the substrate nature and roughness. This study evidenced that the mechanism of Zr-EAD is dependent on the potential applied and on the substrate composition, whereas conversion coating is uniquely dependent on the adsorption reaction time. The zirconium oxide based nanofilms were more homogenous in AA2024 substrates if compared to pure Al grade (AA1100). It was justified by the high content of $\mathrm{Cu}$ alloying element present in the grain boundaries of the latter. Such intermetallic active sites favor the obtaining of $\mathrm{ZrO}_{2}$ films, as demonstrated by XPS and AFM results. From a mechanistic point of view, the electrochemical reactions take place simultaneously with the conventional chemical conversion process driven by ions diffusion. Such findings will bring new perspectives for the generation of controlled oxide coatings in modified electrodes used, as for example, in the construction of battery cells; in automotive and in aerospace industries, to replace micrometric layers of zinc phosphate by light-weight zirconium oxide nanometric ones. This study is particularly addressed for the reduction of industrial waste by applying green bath solutions without the need of auxiliary compounds and using lightweight ceramic materials.

Keywords: conversion coating; zirconium oxide; aluminum alloys; electro-assisted deposition; metal-oxide interface; nanocoating

\section{Introduction}

Circular economy, life-cycle assessment, reduction of fuel consumption, reduction of industry manufacturing costs, all together drive forces to the development of environmentally friendly and lightweight new materials and devices for automotive and aerospace industry applications. Within this context, old and expensive metal pre-treatment processes, such as iron and tri-cation zinc phosphating, and green and yellow chromate, are moving towards a new generation of cleaning and surface activation processes [1,2]. Phosphating is a widely used chemical pre-treatment process for metal surface protection, actuating as both passivating layer and adhesion promoter for subsequent application of 
organic coatings, particularly in the automotive and in the aircraft industry [3,4]. Phosphating and chromate technologies have been substituted by chromium-free and hybrid pre-treatment coatings [5-8]. The urge for innovation in such processes and, particularly, in the replacement of hazardous substances (with potential toxicity for human life) motivate extensive research on various alternatives, among which titanium and zirconium fluorinated-complex are recognized as one of the most promising pre-treatment coatings for body car protection, aerospace alloys, coil coatings, and other structural equipment $[9,10]$.

Zirconium-based chemical conversion coating (Zr-CCC) has been widely used as chemical pre-treatment by dip-coating deposition and under cathodic electro-dip primer formation, mainly for the replacement of tri-cation zinc phosphate pre-treatments in the automotive original equipment manufacturers (OEM) market [11]. Such coatings, with specific weight of only 0.01 to $0.02 \mathrm{~g} / \mathrm{m}^{2}$, are extremely thin and represent a great advantage of cost and light-weighting final material for the producers [1]. The effectiveness of the dip-coating process by immersion of the metal substrate in hexafluorozirconic-acidbased $\left(\mathrm{H}_{2} \mathrm{ZrF}_{6}\right.$-based) solution is $\mathrm{pH}$ limited and the homogeneity of the obtained films is sometimes poor [12]. Previous works have demonstrated that the incorporation of auxiliary additives in the bath solutions, like copper (II), nickel (II), nitrate $\left(\mathrm{NO}_{3}{ }^{-}\right)$and hydrogen phosphate $\left(\mathrm{HPO}_{4}{ }^{2-}\right)$ ions, are necessary to further improve the barrier property and the density of Zr-CCC layer [13,14]. Unfortunately, the addition of auxiliary compounds is not a good option for industrial applications because they may increase the formation of anodic sludge in tanks and the amount of water contaminants, resulting in non-sustainable and non-competitive costs for industry.

There are a lot of examples of the $\mathrm{Zr}$-CCC applications in steel and aluminum alloys, by dip-coating method [9,15-17] and a few related to the electro-assisted deposition (EAD) method $[18,19]$. Unfortunately, a deep understanding of the nanocoating formation and its stability were scarcely approached. For instance, Chen-Wiegart and co-workers [13] developed environmentally friendly $\mathrm{Zr}$-based conversion nanocoatings on low carbon steel by using $\mathrm{H}_{2} \mathrm{ZrF}_{6}$ solutions with very low content (ppm) of cupric nitrate as additive. By using in situ synchrotron $\mathrm{X}$-ray fluorescence microscopy $(\mathrm{XRF})$, they found that the final nanocoating composition mainly consists on $\mathrm{ZrO}_{2}$ and $\mathrm{Cu}_{2} \mathrm{O}, \mathrm{Cu}$, and $\mathrm{CuF}_{2}$ molecules in format of clusters above the film. Therefore, $\mathrm{Cu}$ ions were retained by chemical reaction adsorption and were not leached to the bath solution.

Herein, we describe the controlled deposition of a hydrated zirconium oxide monolayer, free of other metals or additives, in two grades of aluminum substrates: pure $\mathrm{Al}$ (AA1100) and Cu-rich alloy (AA2024). The films, which were obtained using the dipcoating (Zr-CCC or simply DC) and the electro-assisted deposition method (Zr-EAD), were fully characterized by microscopy, spectroscopy and electrochemical analyses. A mechanism based on the substrate nature is proposed, corroborating with previous works on CCC treatments. Finally, the barrier properties are also evaluated to determine the nanocoating resistance in electrolyte solution. Considering that $\mathrm{H}_{2} \mathrm{ZrF}_{6}$ is the main component of most Zr-based conversion treatments, this study is appealing to broad applications.

\section{Materials and Methods}

\subsection{Materials}

Hexafluorozirconic acid $\left(\mathrm{H}_{2} \mathrm{ZrF}_{6}, 50 \% \mathrm{w} / \mathrm{w}\right.$ in water) was supplied by Sigma-Aldrich Co. (Madrid, Spain); sodium hydroxide ( $\mathrm{NaOH}$ pellets), used to regulate the $\mathrm{pH}$ of the solution, was purchased from Panreac S.A. (Barcelona, Spain). The industrial alkaline degreaser (Saloclean $667 \mathrm{~N}$ ) was kindly supplied by Klintex Insumos Industriais Ltda. (São Paulo, Brazil). Aluminum plates (standard name AA1100), with rectangular geometry $\left(5.0 \times 1.4 \times 0.3 \mathrm{~cm}^{3}\right)$, and aluminum alloy (standard name AA2024-T3), with disk format ( $3.5 \mathrm{~cm}$ in diameter and $4 \mathrm{~mm}$ of thickness) were used as substrates for $\mathrm{Zr}-\mathrm{CCC}$ and $\mathrm{Zr}$-EAD formation. AA1100 is included in the commercially pure Al series. Its composition was provided by the supplier Irmãos Galeazi Ltda. (São Paulo, Brazil), in weight percentage (in wt. \%): $\mathrm{Cu}(0.34) ; \mathrm{Fe}(0.42) ; \mathrm{Si}(0.19) ; \mathrm{Mn}(<0.01)$; $\mathrm{Ti}(<0.02) ; \mathrm{Zn}(<0.01)$ and balanced 
aluminum. AA2024-T3 is a structural reinforced aluminum-copper grade with metallurgical temper code T3, which is referred to a solution heat-treated, cold worked and metal naturally aged. The AA2024 bar was supplied by Balumer S.L. (Barcelona, Spain) and its chemical composition is (in wt.\%): $\mathrm{Cu}$ (4.63); $\mathrm{Mg}$ (1.66); $\mathrm{Mn}$ (0.55); $\mathrm{Fe}$ (0.36); $\mathrm{Si}(0.31$ ); and balanced to Al. The chemical composition analysis for AA2024 alloy was determined by ICP-AES (spectrometer SPECTROMAXx, Spectro, Cleve, Germany). Indium tin oxide coated polyethylene terephthalate sheets (ITO coated PET sheets, surface resistivity $60 \Omega$ /square, Sigma-Aldrich, Saint Louis, MI, USA) and pure copper plates were used as complementary substrates for specific tests, described in the next sections.

\subsection{Preparation and Cleaning of Aluminium Substrates}

The surfaces of the aluminum alloy substrates were prepared by grinding the surface with silicon carbide paper from \#600-grit, down to up \#2500-grit. Some samples were cleaned in ultrasound bath with isopropanol, followed by ethanol and, at last, acetone for $5 \mathrm{~min}$ at room temperature in each solvent. This procedure was carried out for the production of Raw samples, providing a mild cleaning, aiming for the preservation of the naturally formed aluminum oxide layer (hereafter coded as "Raw"). The rest of the samples were thoroughly washed with water and acetone and immersed in Saloclean 667N degreasing agent $\left(\mathrm{pH} \mathrm{9.4,} 70 \mathrm{~g} / \mathrm{L}, 70^{\circ} \mathrm{C}\right)$ for $5 \mathrm{~min}$. Afterwards, the specimens were washed with distilled water in a sonication bath for $5 \mathrm{~min}$, dried under a hot air stream, and stored under vacuum before use. This treatment generated the samples coded as "Bare", which represents the industrial conditions of metal degreasing before coating deposition.

\subsection{Zirconium Oxide Nanocoating Depositions (DC and Zr-EAD)}

The conversion bath consists of an aqueous solution prepared with $100 \mathrm{mg}$ of $\mathrm{H}_{2} \mathrm{ZrF}_{6}$ in $1 \mathrm{~L}$ of water $(0.015 \% v / v)$. The $\mathrm{pH}$ was adjusted to 3.5 with $\mathrm{NaOH}$ solution $(1 \mathrm{M})$. In order to produce the $\mathrm{Zr}$-DC samples, panels were immersed in the conversion solution for $4 \mathrm{~min}$, followed by water rinsing and hot air stream drying (before aging step, described below). By contrary, the Zr-EAD samples were obtained by a potentiostatic electrochemical method. The depositions were carried out with an Autolab PGSTAT302N potentiostatgalvanostat (Ecochimie) equipment, by using a three electrodes cell configuration. The working electrodes consisted of aluminum plates or disks, ITO foils and copper plates; the reference electrode was $\mathrm{Ag} \mid \mathrm{AgCl}$ (3 M, saturated); and the counter electrode was composed by graphite bar. The electrolyte used for EAD assays was the same used for the chemical conversion process. The experiments were carried out after open circuit potential (OCP) measurement (30 s), followed by the application of the desired potential during $4 \mathrm{~min}$. The potentials used in this work were $-1.0 \mathrm{~V}_{\mathrm{OCP}}$ and $-1.5 \mathrm{~V}_{\mathrm{OCP}}$, generating the samples named "EAD $-1.0 \mathrm{~V}$ " and "EAD $-1.5 \mathrm{~V}$ ", respectively. Such potentials were chosen on the basis of our previous experience $[20,21]$. Samples coated by both dip-coating and EAD were further post-treated for $2 \mathrm{~h}$ at $100{ }^{\circ} \mathrm{C}$, as aging step treatment to achieve the dehydration of the oxide layer and the reduction of defects [22].

In parallel, ITO substrates were sequentially rinsed in deionized water, acetone and ethanol, with each rinsing step being carried out during $5 \mathrm{~min}$, under sonication. After the washing process, the samples were submitted to the $\mathrm{ZrO}_{2}$ electro-assisted deposition, with the same procedure and equipment described for the aluminum specimens. Those samples were used for the AFM and SEM measurements, in order to evaluate the isolated effect of EAD in a substrate where the conversion chemical reactions do not occur and to approach the influence of substrate homogeneity and roughness on the Zr-EAD coating. Moreover, more samples were prepared by EAD method, employing longer reaction time (60 $\mathrm{min}$ ), to achieve thicker films and measure the mechanical properties of the oxide layer by nanoindentation test. In the same way, copper plates were also cleaned and, further DC or EAD methods were applied to compare the effect of $\mathrm{Cu}$ metal in the $\mathrm{ZrO}_{2}$ production and the stability in electrolyte media. 


\subsection{Physical and Chemical Characterization}

Scanning electron microscopy (SEM) studies were conducted with a Focus Ion Beam (FIB) Zeiss Neon 40 instrument (Carl Zeiss, Berlin, Germany). One specimen of each coated substrate was selected for cross-section analysis. The cross-sections were cut using Focused Ion Beam (FIB) with gallium ions. The samples were previously coated with a sputtered carbon layer and received a thin protective layer of platinum (gas injection). First, an electron beam assisted Pt deposition was carried out to achieve Pt layer thickness of about $250 \mathrm{~nm}$. The platinum layer was necessary to obtain smoother cross-sections by protecting the surface against the damage of the Ga ions. An initial coarse milling was carried out at $10 \mathrm{nA}$, followed by a finer milling at $500 \mathrm{pA}$, which provided polished cross-sections was performed. The resulting cross-sections were $15 \mu \mathrm{m}$ long and $3 \mu \mathrm{m}$ deep. For SEM analysis an electron beam of $5 \mathrm{kV}$ was applied. The thickness of $\mathrm{Zr}$-DC and Zr-EAD coatings was evaluated after 50 measurements using high magnification images. Analysis of variance (one-way ANOVA) was carried out with a confidence level of $95 \%$, followed by a Turkey test for means comparison of the measured thicknesses. Atomic force microscopy (AFM) was conducted to obtain topographic information (2D Phase images) and roughness (3D height images) of the modified surfaces. The experiments were carried out with an AFM Dimension microscope, equipped with NanoScope IV controller and NanoScope Analysis software (Veeco Instruments Inc., New York, NY, USA), under ambient conditions and by using tapping mode. The equipment operated with a frequency of $150 \mathrm{kHz}$ and a with force constant of $5 \mathrm{~N} / \mathrm{m}$. The scanning frequency was set between 0.6 and $0.8 \mathrm{~Hz}$ and the area of analysis varied with windows of $50 \mu \mathrm{m}^{2} \times 50 \mu \mathrm{m}^{2}$ and $20 \mu \mathrm{m}^{2} \times 20 \mu \mathrm{m}^{2}$. Several measurements were performed on the top of the samples, which produced reproducible images similar to those displayed in this work.

The chemical compositions of the substrates and coatings were determined by X-ray photoelectron spectroscopy (XPS) and energy dispersive X-ray spectroscopy (EDX). XPS analyses were performed in a SPECS system equipped with a high intensity twin anode X-ray source XR50 of Mg/ $\mathrm{Al}(1253 \mathrm{eV} / 1487 \mathrm{eV})$ operating with the selected $\mathrm{Al}$ anode at $150 \mathrm{~W}$, and by using a Phoibos 150 MCD-9 XP detector (SPECS, Berlin, GmbH). For the preparation of the samples, the bare alloys were first polished, washed three times with isopropanol, ethanol, deionized water and acetone, under ultrasound bath for $5 \mathrm{~min}$, dried under nitrogen flow and vacuum. Afterwards, sputtering of the surfaces with argon gas ( $2 \mathrm{~min}$ ) was applied to eliminate the surface contamination by carbon compounds. All spectra were calibrated with the $\mathrm{C}$ 1s peak $(284.5 \mathrm{eV})$. The following elements: $\mathrm{C} 1 \mathrm{~s}, \mathrm{O} 1 \mathrm{~s}$, $\mathrm{Al} \mathrm{2p}, \mathrm{Zr} 3 \mathrm{~d}$, and $\mathrm{Cu} 2 \mathrm{p}$ were analyzed for the high-resolution peaks and plotted after deconvolution.

Water contact angle (WCA) measurements were carried out with an OCA 15EC instrument (DataPhysics Instruments, Filderstadt, $\mathrm{GmbH}$ ), using the sessile droplet method at room temperature, to evaluate the wettability changes of the modified surfaces. Data were recorded after the water droplet deposition $(0.5 \mu \mathrm{L})$ and stabilization $(30 \mathrm{~s})$, using SCA 20 software, and are reported as an average of ten independent measures for each sample.

The hardness and elastic modulus of thin Zr-EAD films were measured using an MTS Nanoindenter XP instrument (Nanoinstruments Innovation Center, Oak Ridge, TN, USA), with a Berkovich diamond tip calibrated with fused silica standard. The results were analyzed with the Oliver and Pharr method [23,24]. The sample prepared on ITO substrate, coated by EAD technique at $-1.0 \mathrm{~V}$ during $60 \mathrm{~min}$, was used as model to estimate the mechanical properties of the film. Long generation time was necessary to produce thick coatings in order to obtain reliable values of mechanical properties under nanoindentation forces.

\subsection{Electrochemical Characterization of Zirconium Oxide Nanocoating}

The potentiodynamic and electrochemical impedance spectroscopy (EIS) studies were performed in an Autolab PGSTAT302N (Eco-Chemie Methrom Autolab B.V., Utrecht, The Netherlands) potentiostat-galvanostat (Ecochemie) equipment. The electrochemical cell 
consisted of three electrodes, having the sample set as the working electrode, a platinum wire as counter electrode and a $\mathrm{Ag} \mid \mathrm{AgCl}(\mathrm{KCl}, 3 \mathrm{M})$ as reference electrode. The tested area was $0.785 \mathrm{~cm}^{2}$ and the electrolyte used was $0.05 \mathrm{M} \mathrm{NaCl}$ aqueous solution. The curves were registered after $30 \mathrm{~min}$ of open circuit potential (OCP) stabilization. The potential sweep ranged from $-0.3 \mathrm{~V}_{\mathrm{OCP}}$ to $+1.0 \mathrm{~V}_{\mathrm{OCP}}$ with a scan rate of $1 \mathrm{mV} / \mathrm{s}$. For short run times $(0.5 \mathrm{~h})$, the cleaned, etched and coated substrates were evaluated per triplicate and the effect of the cathodic potential $(-1.0 \mathrm{~V}$ or $-1.5 \mathrm{~V})$ was compared.

EIS experiments were performed to evaluate the polarization resistance of the $\mathrm{ZrO}_{2}$ nanolayer, after $30 \mathrm{~min}$ of time exposure to the electrolyte solution. The amplitude of the EIS perturbation signal was $10 \mathrm{mV}$, the frequency ranged from $10^{5}$ to $10^{-1} \mathrm{~Hz}$ taking measurements of 10 frequencies per decade. The same cell and electrodes reported for polarization tests were used here.

\section{Results and Discussion}

\subsection{Influence of the Substrate in the Deposition of Zr-EAD Films}

There are some studies that corroborate the effective role of intermetallic particles in alloyed aluminum as promoters of $\mathrm{Zr}$-CCC deposition [9,25], but apparently their effect in the Zr-EAD has not been explored yet. Pioneer works of Zr-based coatings onto aluminum substrates were also limited to CCC treatments [26,27]. In all cases, the major drawback is the high porosity of the oxide layer and the limited thickness of the $\mathrm{ZrO}_{2}$ film $(10-80 \mathrm{~nm})$, obtained by CCC processes, that preclude a good coating analysis. Therefore, this section will focus in the surface characterization of $\mathrm{ZrO}_{2}$ with controlled deposition by EAD method.

The properties of the $\mathrm{ZrO}_{2}$ deposition will depend on the substrate nature and its roughness. Therefore, indium-tin oxide substrates, with very low roughness $(4.3 \pm 0.9 \mathrm{~nm})$ were chosen to explore the deposition of $\mathrm{ZrO}_{2}$ nanometric layer, taking the advantage of the low effect of the substrate roughness on the nanocoating obtaining. The other advantage of ITO substrate is that it does not undergo the reactions involved in the self-deposition of the $\mathrm{ZrO}_{2}$ by the $\mathrm{CCC}$ method, i.e., the zirconium coating can only be obtained with the application of current or voltage (EAD method). As can be seen in the topographic images (Figure $1 \mathrm{a}-\mathrm{c}$ ), the roughness of the $\mathrm{ZrO}_{2}$ layer is practically the same than that of the substrate without EAD coating, independently of the potential applied. This evidenced that the formed film reproduces the underlying substrate roughness (Table S1, supporting information). The root mean square roughness $(\mathrm{Rq})$ values, which were determined by AFM using a scan window size of $20 \mu \mathrm{m}^{2} \times 20 \mu \mathrm{m}^{2}$, were $5.0 \pm 0.4 \mathrm{~nm}, 6.6 \mathrm{~nm} \pm 0.4 \mathrm{~nm}$, and $6.3 \mathrm{~nm} \pm 0.5 \mathrm{~nm}$, respectively for ITO bare, Zr-EAD/ITO $-1.0 \mathrm{~V}$ and Zr-EAD/ITO $-1.5 \mathrm{~V}$ (Table S1). Increase of electrochemical reaction time (from $4 \mathrm{~min}$ to $60 \mathrm{~min}$ ) led to the obtaining of thick $\mathrm{ZrO}_{2}$ films with elastic modulus of $14.1 \pm 2.1 \mathrm{GPa}$ and hardness of $1.3 \pm 0.1 \mathrm{GPa}$, derived from nanoindentation measurements (Figure S1). Such values do not correspond to solid fully dense zirconia, after sintering process (>17 GPa and $250 \mathrm{GPa}$, for hardness and elastic modulus, respectively) [28], as the coating does not undergo traditional ceramic processing, indicating that the film should have more porous microstructure than that of bulk material itself [29-31].

Regarding the deposition of $\mathrm{ZrO}_{2}$ in aluminum substrates, the thickness measurement by AFM is impracticable due to the nanoscale range of the films $(20-30 \mathrm{~nm})$ compared to the high roughness of soft metal substrate after polishing pre-treatments. Here, such measurements were carried out with FIB-SEM microscopy. The SEM images, showing a detail of the cut provoked by the electron beam, demonstrate that $\mathrm{ZrO}_{2}$ films are perfectly adhered to the substrate (Figure 2a-c). The substantial challenge is found when comparing the two substrates in Figure 2d. AA1100 plates have the highest film thicknesses (Table 1). The explanation is that the zirconium layer does not correspond exclusively to $\mathrm{ZrO}_{2}$ compounds, as the film has a gradient in composition. The closer to the substrate interface, the higher the $\mathrm{Al}$ concentration, which is related to a combination of $\mathrm{Al}_{2} \mathrm{O}_{3} / \mathrm{AlOOH}$ passivating layers; whereas the outer surface is rich on $\mathrm{Zr}$ atoms (detected by XPS analysis, as will 
be discussed in Section 3.2). This implies that there is not a defined interface between the $\mathrm{Zr}-\mathrm{CCC}$ and the native oxide/hydroxide layer and both contribute to the measured thicknesses. A simplified profile in $\mathrm{Zr}$ and $\mathrm{Al}$ concentrations, as a function of depth, is shown in Figure 2e. The depth-dependent element concentration profile on zirconium-based conversion coatings has been already demonstrated by other authors using techniques such as Auger Electron Spectroscopy (AES) [17,32], Time-of-Flight Secondary Ion Mass Spectrometry (ToF-SIMS) [33] and Glow Discharge Optical Emission Spectroscopy (GDOES) [34]. The thickness of the native oxide layer was determined to be at around $30 \mathrm{~nm}$.

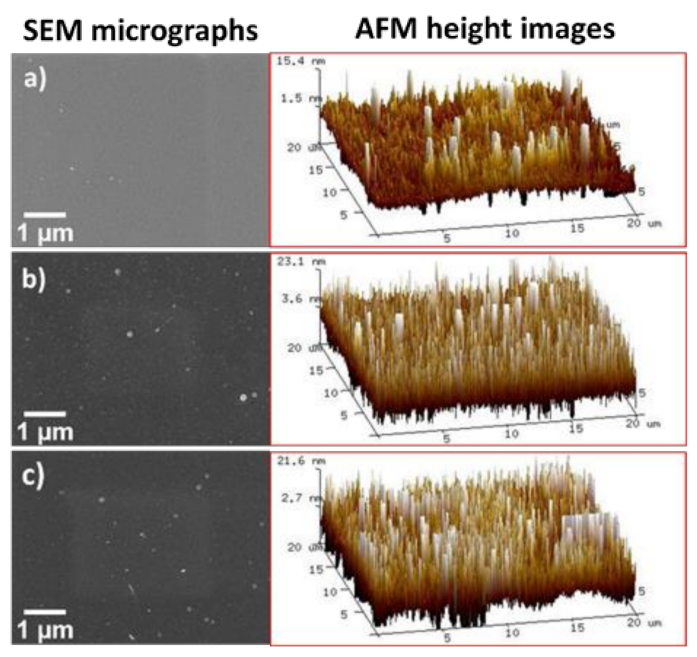

Figure 1. SEM (left) and AFM 3D height images (right) on ITO substrates: (a) after ultrasonication bath cleaning; (b) after Zr-EAD at $-1.0 \mathrm{~V}$; and (c) after Zr-EAD at $-1.5 \mathrm{~V}$.
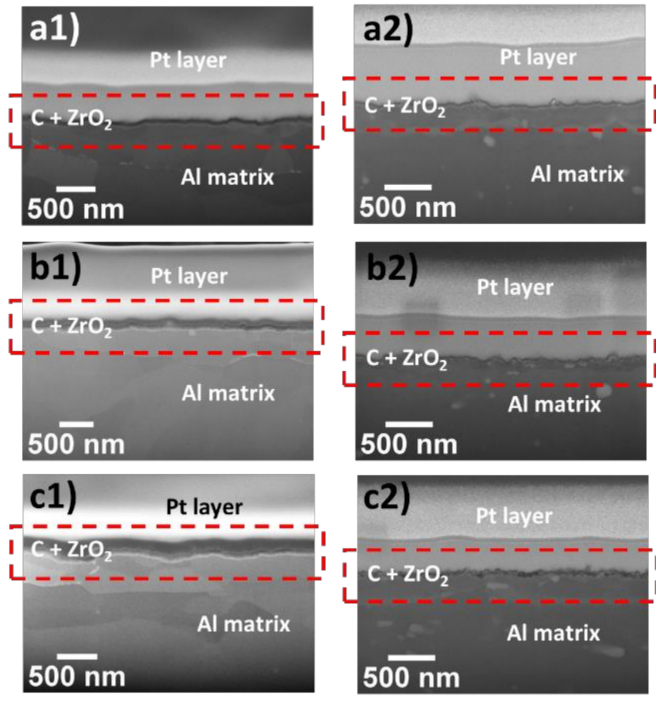

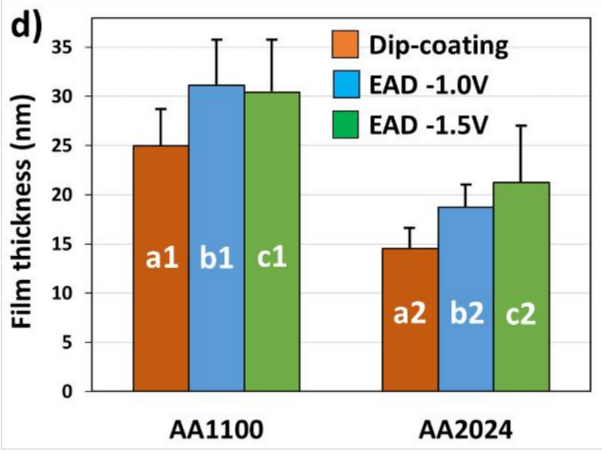

e) Intermediate zone

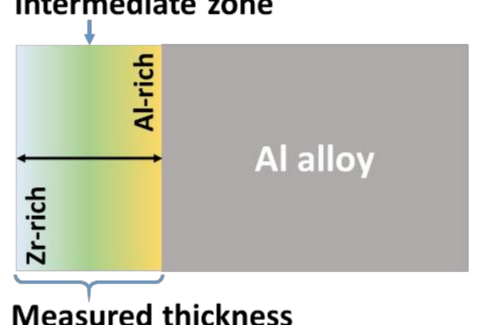

Figure 2. (a-c) Cross-section of FIB-SEM micrographs showing the $\mathrm{ZrO}_{2}$ film thickness between Pt layer and metal substrate, previously degreased with alkaline solution (Bare). (d) Values of thicknesses and deviations of samples AA1100 and AA2024, evaluated by HR-SEM. (e) Schematic representation of $\mathrm{ZrO}_{2}$ layer over Al alloy surfaces. Letter codification: (a) Dip-coating method; (b) Zr-EAD at -1.0 V; (c) Zr-EAD at -1.5 V; and number codification: (1) AA1100 and (2) AA2024 plates. SEM magnifications: (a1) 81.81 kX; (a2) 100 kX; (b1) 72.43 kX; (b2) 100 kX; (c1) 85.28 kX; and (c2) 100 kX. Red rectangles indicate the region used for the thicknesses measurements. The different layers can be easily discriminated in the Figure S2 (supporting information), and are composed by: Pt, carbon graphite and Zr-DC or Zr-EAD layers. 
Table 1. Thicknesses of $\mathrm{ZrO}_{2}$ nanocoatings, obtained by cross-section analysis of FIB-SEM micrographs, for samples generated with two different methods. (DC and EAD), and with two different deposition potentials $(-1.0 \mathrm{~V}$ and $-1.5 \mathrm{~V})$.

\begin{tabular}{ccc}
\hline Substrate & $\mathbf{Z r O}_{2}$ Deposition Method & Thickness and SD (nm) \\
\hline \multirow{2}{*}{ AA1100 } & DC & $24.9 \pm 6.7$ \\
& EAD at $-1.0 \mathrm{~V}$ & $31.1 \pm 8.2$ \\
& EAD at $-1.5 \mathrm{~V}$ & $30.4 \pm 9.8$ \\
AA2024 & DC & $14.5 \pm 4.1$ \\
& EAD at $-1.0 \mathrm{~V}$ & $18.7 \pm 4.0$ \\
& EAD at $-1.5 \mathrm{~V}$ & $21.2 \pm 10.1$ \\
\hline
\end{tabular}

The local deposition of Zr-oxide based coatings on AA1100 is due its high amount of passivating layers $\left(\mathrm{Al}_{2} \mathrm{O}_{3} / \mathrm{AlOOH}\right)$, compared to the surface with copper rich sites (AA2024). Moreover, previous work proved that the local composition of $\mathrm{ZrO}_{2}$ is conditioned by the presence of copper in the alloy surface (AA6014 contains $\mathrm{Mg} \leq 0.8 \mathrm{wt} . \%$, $\mathrm{Fe} \leq 0.35 \mathrm{wt} . \%, \mathrm{Si} \leq 0.6 \mathrm{wt} . \%, \mathrm{Cu} \leq 0.2 \mathrm{wt} . \%, \mathrm{Mn} \leq 0.2 \mathrm{wt} . \%$, the rest of Al) [35]. They found higher amount of $\mathrm{Al}$ atoms than $\mathrm{Zr}$ atoms when alloys without $\mathrm{Cu}$ were investigated (AA1050 contains $\mathrm{Al} \geq 99.5 \mathrm{wt} . \%, \mathrm{Fe} \leq 0.3 \mathrm{wt} . \%$ ); which corroborates our results. Thus, we found similar effect and the same tendency on $\mathrm{ZrO}_{2}$ layer deposition, by using XPS analysis (Section 3.2). The novelty in this work is that the aluminum alloy used has the highest $\mathrm{Cu}$ weight percentage (AA2024 contains $\mathrm{Cu} \geq 4.5 \mathrm{wt}$ \%) among $\mathrm{Al}$ alloys. Therefore, the effect on the nanocoating deposition is more evident with respect to samples without copper, as for example in AA1100 and AA1050 alloys; or with very low content, as is the case of AA6014 alloy.

On the other hand, the analysis of variance followed by Turkey test for means comparison (significance level of 0.05) indicates greater film thicknesses obtained by EAD, regardless of the applied potential, when compared to the DC method (Table 1) on both substrates. This probably occurs due to the improved ions migration induced by potential application.

\subsection{Zr-EAD Nanocoating Composition}

The XPS analysis (Figure S3) revealed a great contribution of some compounds present in the metal-zirconium oxide coating interface, due to the low thicknesses of such films and to the influence of metal pre-treatment. The most relevant atoms were aluminum, derived from the substrate and from oxidized $\mathrm{Al}$ compounds; fluorine, derived from the bath solution and further reaction with $\mathrm{Al}^{3+}\left(\mathrm{AlF}_{3}\right)$; and copper, derived from $\mathrm{Cu}$ oxidation to $\mathrm{Cu}^{1+}\left(\mathrm{Cu}_{2} \mathrm{O}\right)$ and $\mathrm{Cu}^{2+}\left(\mathrm{Cu}(\mathrm{OH})_{2}\right)$. The latter was exclusively detected in the AA2024 substrates (Figure $\mathrm{S} 4$ ), which have high content of $\mathrm{Cu}$ as alloying element.

The abovementioned compositions were observed thanks to the careful deconvolution of the XPS high resolution experimental data and contrasting with XPS database. The deconvolutions of the $\mathrm{Al} 2 \mathrm{p}, \mathrm{Zr} 3 \mathrm{~d}$ and $\mathrm{Cu} 2 \mathrm{p}$ peaks are shown in Figures 3 and 4 and Figure S4. Moreover, the atomic percentage concentrations of those elements are expressed in Table S2.

It is evident that mild surface cleaning with organic solvents (Raw), for example, does not remove the native $\mathrm{Al}$ oxide and alloying elements from the metal surface (Figure $3 \mathrm{a}, \mathrm{b}$ ), whereas alkaline etching (Bare) causes a great effect. In a strongly alkaline environment, a powerful oxidizing agent is introduced, then the metal oxidation and the formation of one (or more) of the solid oxides $\left(\mathrm{Al}_{2} \mathrm{O}_{3} / \mathrm{AlO}_{\mathrm{x}}\right)$, and metal hydroxides $(\mathrm{AlOOH})$ is expected (Figure 3c,d) [36,37]. Indeed, in the particular case of Al alloys, de-alloying of the elements close to the surface is also achieved. It was observed in the high-resolution spectra of $\mathrm{Cu} 2 \mathrm{p}$, by detection of the presence of $\mathrm{Cu}_{2} \mathrm{O}$ and $\mathrm{Cu}(\mathrm{OH})_{2}$ molecules (Figure $\mathrm{S} 4$ ) and has been extensively reported by several authors [38-41]. Thus, the $\mathrm{Cu}$ atomic concentration is much higher for the Bare sample than for the other treatments in AA2024. After the zirconium deposition, the high resolution spectrum of $\mathrm{Al} 2 \mathrm{p}$ is almost invariable in any 
EAD potentials, but has much lower atomic percentage in AA2024, if compared to AA1100 (Table S2). We should emphasize that $\mathrm{Al} 2 \mathrm{p}$ region has also a small contribution of $\mathrm{Cu} 3 \mathrm{p}$ content in the same region, as seen in the Figure $3 \mathrm{f}, \mathrm{h}$, and it must be taken into account for the calculation of the $\mathrm{Al}$ atomic percentage in AA2024 samples.

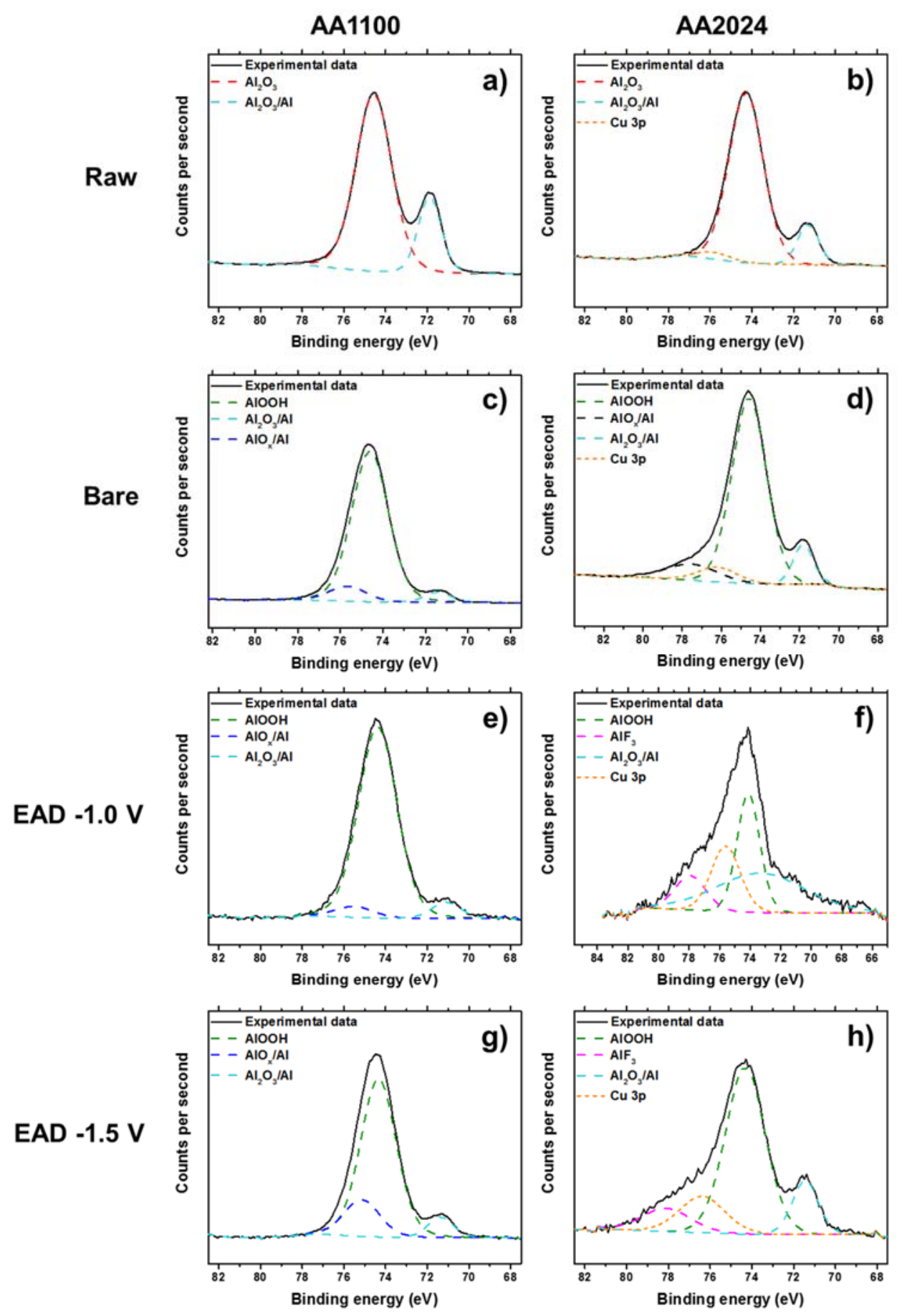

Figure 3. XPS high-resolution spectra of $\mathrm{Al} 2 \mathrm{p}$ region, before (Raw, $\mathbf{a}, \mathbf{b})$ and after alkaline etching process (Bare, c,d), and after electro-assisted deposition of $\mathrm{ZrO}_{2}$, generated at $-1.0 \mathrm{~V}(\mathbf{e}, \mathbf{f})$ and $-1.5 \mathrm{~V}$ (g,h). Left: AA1100 samples and right: AA2024 samples.

Taking into account the deconvolution of $\mathrm{Zr}$ high resolution spectrum, with two peaks of $\mathrm{Zr} 3 \mathrm{~d}_{5 / 2}$ and $\mathrm{Zr} 3 \mathrm{~d}_{3 / 2}$ at binding energies of $182.5 \mathrm{eV}$ and $185 \mathrm{eV}$ (Figure 4), respectively, the inorganic coating is mainly composed by zirconium oxide, whereas some minor residual 
fluorine complexes are probably present $[17,25,42]$. Fluorine element observed in EAD samples (Figure S3) most arises from the bath, whereas that detected in Raw and Bare substrates comes from some equipment contamination. Zhang et al. [10] have reported that conversion coatings of 5052 aluminum alloy (Mg-rich alloy) obtained from fluorine salt solutions contains hydrated $\mathrm{AlF}_{3}$ compound trapped among the metal oxides. As the contribution of fluorine has been measured to be between 2-3\%, and even less for Raw and Bare substrates, it has been considered to not interfere significantly in the interpretation of the results regarding the main components. The EAD coating composition found was consistent with that reported for DC method $[25,35,42]$. In AA1100 samples, the Al-rich and $\mathrm{Zr}$-rich zones pointed out in Figure 2e, are not differentiated. The apparent atomic ratio of $\mathrm{Al} / \mathrm{Zr}$ is close to unit (0.91 and 1.41 , for $\mathrm{EAD}-1.0 \mathrm{~V}$ and $\mathrm{EAD}-1.5 \mathrm{~V}$, respectively); whereas in AA2024 such values have been reduced to a factor of $1 / 3$ and 1/2 (Table S2). Based on XPS evidences, undoubtedly, the unique explanation for the high content of $\mathrm{Zr}$ atoms in AA2024 is the distribution of $\mathrm{ZrO}_{2}$ molecules over the abovementioned surface, i.e., the homogeneity of the film covering the substrate, which seems to be favored by both, the use of the EAD technique and the presence of $\mathrm{Cu}$-rich sites.

In conclusion, the slightly higher thicknesses measured for AA1100 samples can be the result of a thick aluminum oxide/hydroxide layer in the boundary zone between $\mathrm{Al}$ metal surface and zirconia layer, as explained before. So, the $\mathrm{Zr}$-rich zone is expected to be more homogenous and thinner in AA2024 than in AA1100, which agrees with the known favorable effect of the intermetallic (with cathodic nature, like copper-aluminum) for the zirconium oxide film formation, described above. Additionally, comparing the two cathodic potentials used in EAD treatments, the low voltage $(-1.0 \mathrm{~V})$ seems to potentiate a better surface coverage, as will be explained in the next section.

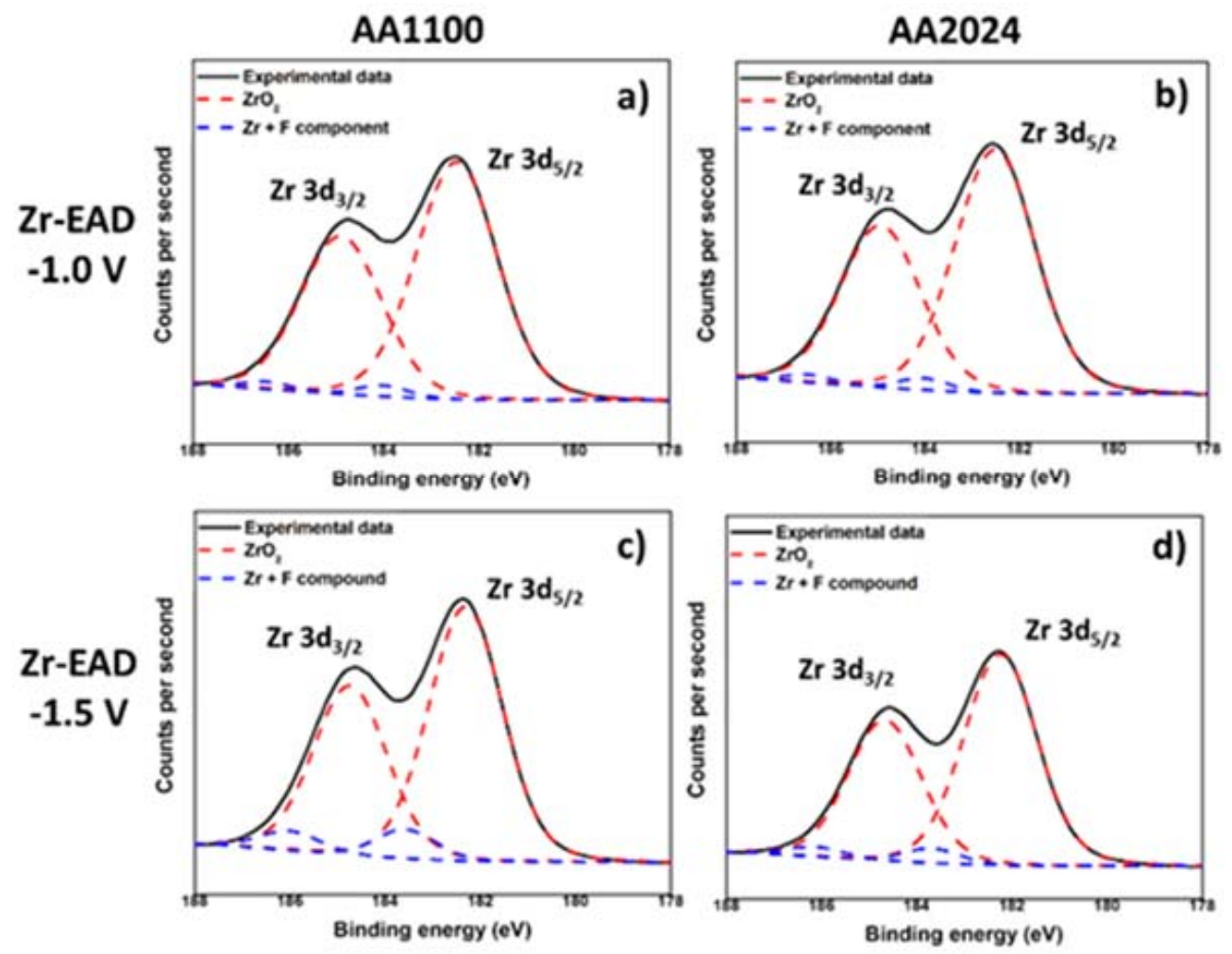

Figure 4. XPS high-resolution spectra of $\mathrm{Zr} 3 \mathrm{~d}$ region, after electro-assisted deposition of $\mathrm{ZrO}_{2}$ : (a) AA1100/EAD - 1.0 V; (b) AA2024/EAD - 1.0 V; (c) AA1100/EAD - 1.5 V; and (d) AA2024/EAD $-1.5 \mathrm{~V}$. 


\subsection{Zr-EAD Nanocoating Surface Topography}

The morphology of the nanometric films was evaluated by SEM. In Figure 5, a clear cauliflower structures was evidenced after the $\mathrm{ZrO}_{2}$ growth on top of aluminium surfaces, which is characteristic of porous materials [43-45]. The globular agglomerates observed in samples AA1100 (Figure 5a-c) are bigger than that obtained in AA2024 (Figure 5d-f) and it affects the heterogeneity of Zr-based coatings. Long reaction time (60 min) leads to an increase on cauliflower globular structures, agglomerated and, therefore, to highly heterogeneous films with poor mechanical properties, showing thicker coating and cracks (Figure S5), not desirable for industrial application aims.
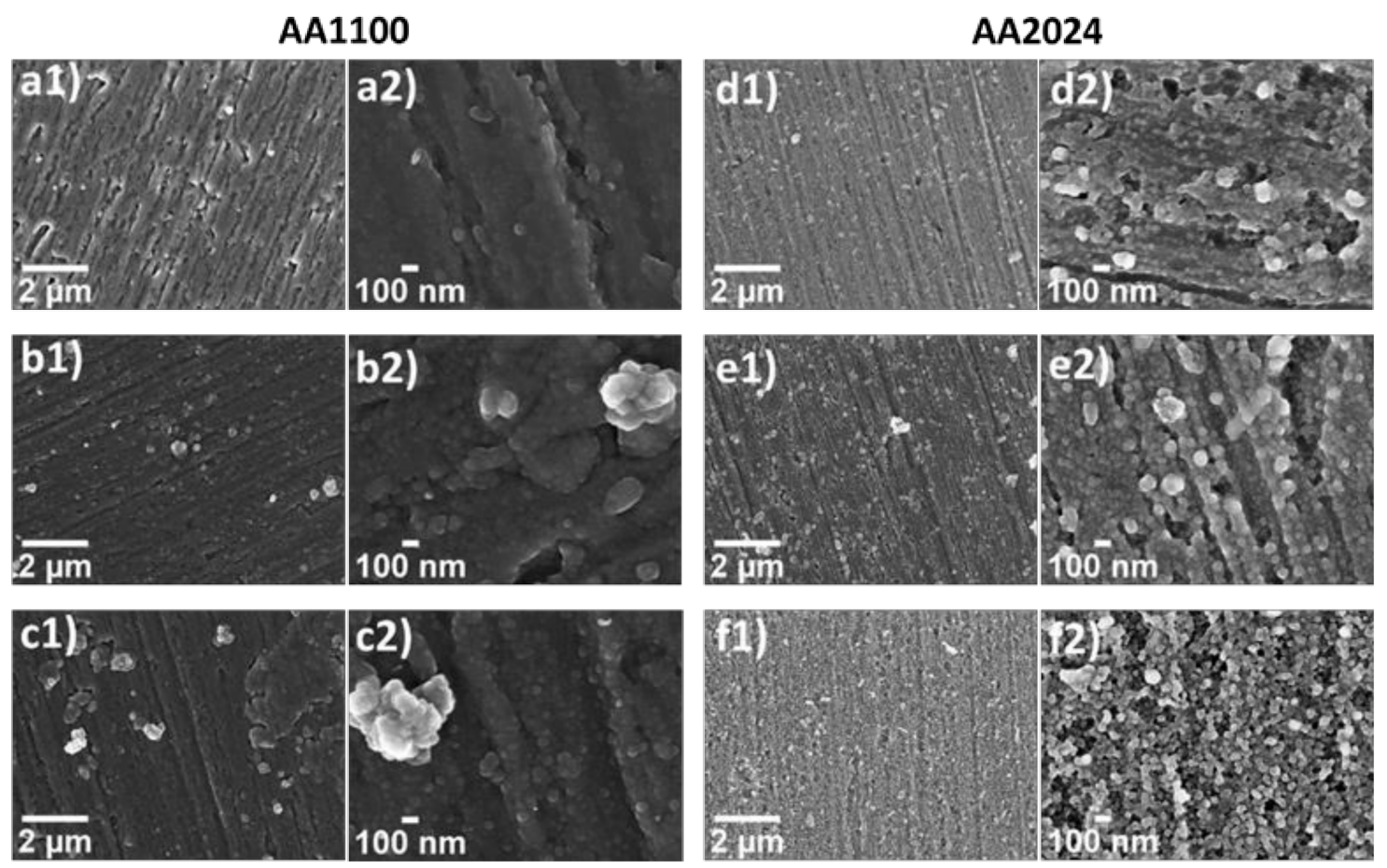

Figure 5. SEM micrographs at low $(1,30 \mathrm{kX})$ and high magnifications $(2,150 \mathrm{kX})$, evidencing the morphology of zirconium oxide in the following samples: (a) Zr-DC/AA1100; (b) Zr-EAD-1.0V/AA1100; (c) Zr-EAD -1.5 V/AA1100; (d) ZrDC/AA2024; (e) Zr-EAD -1.0 V/AA2024; and (f) Zr-EAD -1.5 V / AA2024.

AFM was performed in order to get a deeper understanding on the surface modification by application of EAD method. The surface roughness decreased from $57.2 \pm 28.4 \mathrm{~nm}$ in AA1100 Bare surfaces to $29.8 \pm 7.4 \mathrm{~nm}$ and to $41.4 \pm 3.8 \mathrm{~nm}$, after Zr-EAD at $-1.0 \mathrm{~V}$ and Zr-EAD at $-1.5 \mathrm{~V}$, respectively (Table S1, Figure S6). Similar result was obtained for AA2024 where the roughness decreased from $35.6 \pm 6.6 \mathrm{~nm}$ to $24.9 \pm 2.2 \mathrm{~nm}$ after Zr-EAD at $-1.0 \mathrm{~V}$, whereas with $\mathrm{Zr}$-EAD at $-1.5 \mathrm{~V}$ the value increased $(49.4 \pm 9.3 \mathrm{~nm})$ respect to Bare sample $(35.6 \pm 6.6 \mathrm{~nm})$. By contrary, in ITO substrates, the roughness differences are negligible, as expected, thanks to the high nanometric smoothness of such surfaces.

Particularly, detail observation of AFM 2D phase images reveals important differences among pure $\mathrm{Al}$ and $\mathrm{Cu}$-rich $\mathrm{Al}$ surfaces (Figure 6). $\mathrm{ZrO}_{2}$ successfully filled the valleys generated by the mechanical polishing marks, offering a more homogenous and smooth surface in AA2024 than in AA1100 samples (Figure 6e,f). Moreover, AFM analysis corroborated the morphology aspects observed by SEM, a high voltage $(-1.5 \mathrm{~V})$ implies more roughness due to the higher density of $\mathrm{ZrO}_{2}$ agglomerates generated. In all cases, AFM phase images presented similar and small changes in phase angle, corresponding to a homogenous coating where no more than one material is exposed on the metallic surface. 

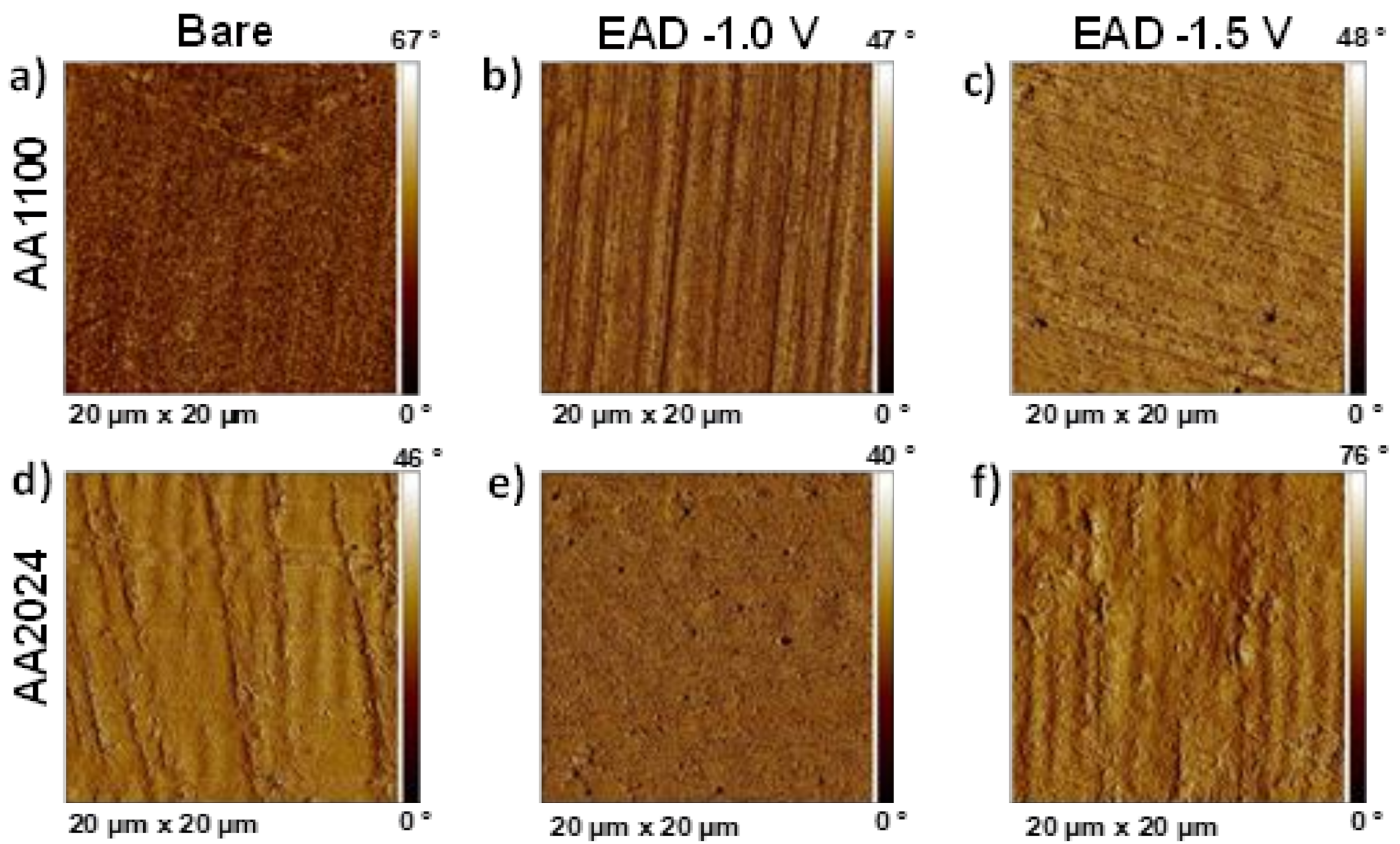

Figure 6. AFM 2D phase images of: (a) AA1100 Bare sample, after raw material degreasing; (b) Zr-EAD at -1.0 V/AA1100; (c) Zr-EAD at -1.5 V/AA1100; (d) AA2024 bare sample, after raw material degreasing; (e) Zr-EAD at - 1.0 V/AA2024; (f) Zr-EAD at $-1.5 \mathrm{~V} / \mathrm{AA} 2024$.

\subsection{Wettability}

The density of oxide clusters observed in Zr-EAD specimens (Figure 5) influenced both the homogeneity and the wettability of the films. The Zr-oxide films assessed in this study were hydrophilic in nature, with WCAs below $90^{\circ}$, as can be seen in Figure 7 . This can be easily explained by comparing the different pre-treatments and the chemical nature changes provoked by each one. Raw samples have similar WCA in both AA1100 and AA2024 surfaces because the metal-air interface was not altered from etching treatments and the influence of the alloying elements is insignificant. By contrary, superhydrophilic surface was observed when the aluminum was exposed to alkaline etching (Bare samples), with WCA of $15-18^{\circ}$ [46]. In this case, the presence of $\mathrm{Al}_{2} \mathrm{O}_{3} / \mathrm{AlOOH}$ passivating layers, observed either in AA1100 or in AA2024 samples (Figure 3), are the responsible for the great affinity of water molecules to this surface. Additionally, the etching of the surface with alkaline solution and the formation of oxide-hydroxide layers enhanced the roughness (Table S1) and it is another reason for their high wettability $[47,48]$.
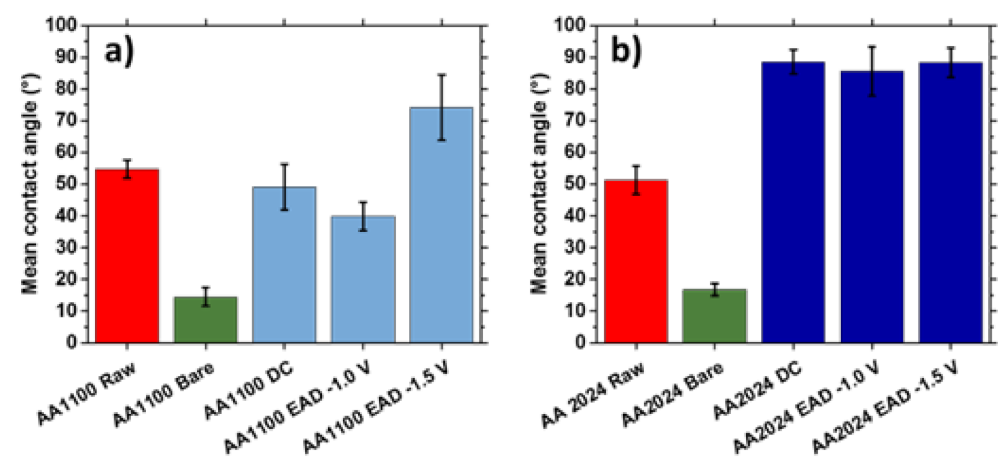

Figure 7. Wettability of (a) AA1100 and (b) AA2024 substrates before and after the application of the following treatments: Raw (metal plates cleaned with acetone); Bare (metal plates degreased with Saloclean 667N and grinded); DC (dip-coating method); and EAD (electro-assisted deposition at two different potentials). 
Moving to the zirconium oxide layers generated after conventional Zr-CCC (DC method) and comparing with $\mathrm{Zr}$-EAD method, the most important changes were again observed in AA2024 samples (Figure 7b). The water affinity decreased, demonstrating that the chemical nature of this substrate plays an important role.

\subsection{Mechanism of $\mathrm{ZrO}_{2}$ Deposition in AA1100 and AA2024 Surfaces}

In conventional zinc phosphating pre-treatment, the initial step is a pickling attack of the metal surface by free phosphoric acid and evolution of hydrogen gas in aqueous solution. The following steps are the coating deposition (usually $2-4 \mu \mathrm{m}$ in thickness) and the generation of high amount of sludge. Thus, replacement of zinc phosphate pretreatments by zirconium oxide coatings is estimated to corroborate on both, the reduction of industry waste and reduction of piece weight by the deposition of an ultrathin metal oxide film (15-30 nm) [49].

The chemical conversion coating of $\mathrm{Zr}$ oxide is strongly dependent on the consumption of protons [49] and on the presence of intermetallic compounds [50] on the metal surface. It is generally accepted that the first process occurring during the conversion coating formation is the thinning and partial removal of the native aluminum oxide layer by the free fluorides in the conversion bath, generating aluminum fluorides (Equation (1)), as represented in the upper part of both substrates at Scheme 1. Then, the metal surface faces a localized shift on the $\mathrm{pH}$ towards alkaline values due to the water electrolysis, through the generation of oxygen and consuming of protons (Equation (2)). Afterwards, the precipitation of hydrated zirconium oxides takes place, according to the reaction showed in Equation (3).

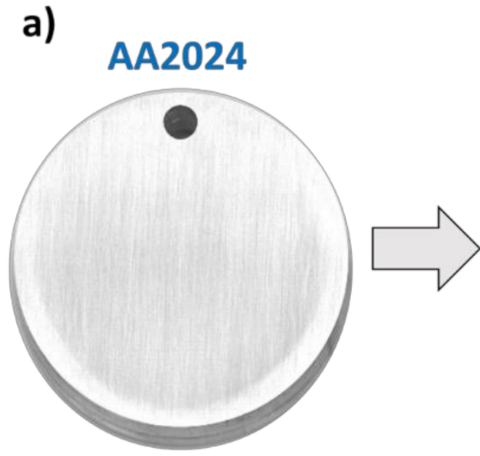

b)

\section{AA1100}

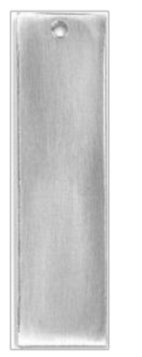

Cathode
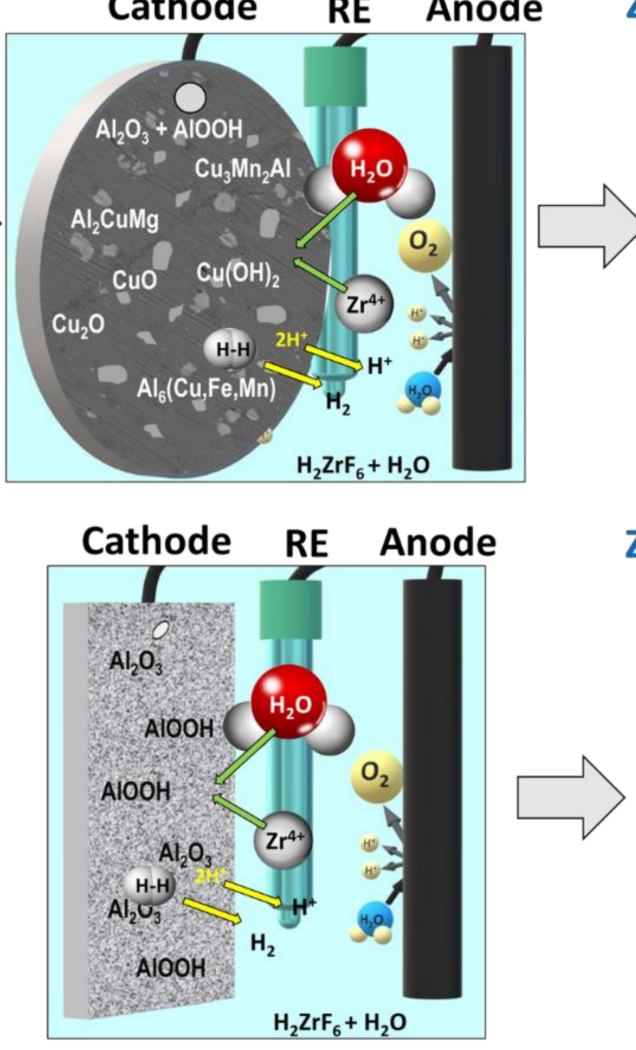

$\mathrm{ZrO}_{2} \cdot 2 \mathrm{H}_{2} \mathrm{O} / \mathrm{AA2024}$

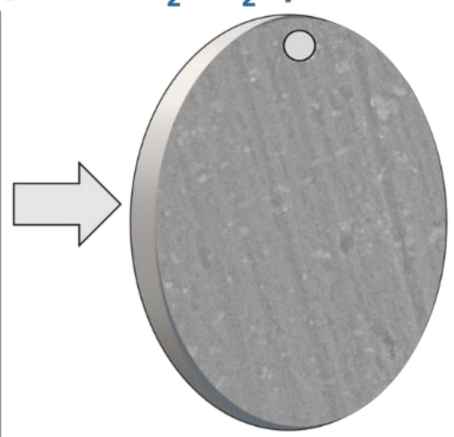

$\mathrm{ZrO}_{2} \cdot 2 \mathrm{H}_{2} \mathrm{O} / \mathrm{AA} 1100$

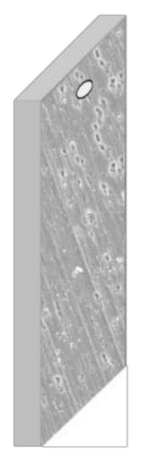

Scheme 1. Illustration of the best conditions for Zr-EAD deposition on: (a) AA2024 disks and (b) AA1100 aluminum plates. From left to right: Bare substrates; application of $-1.0 \mathrm{~V}$ of cathodic potential and 4 min of electrochemical reaction; $\mathrm{Zr}-\mathrm{EAD}$ coated specimen. Arbitrary scale has been used for the visual representation of the reactions. 
Alumina pickling:

$$
\mathrm{Al}^{3+}{ }_{(\mathrm{aq})}+\mathrm{ZrF}_{6}{ }^{2-}{ }_{(\mathrm{aq})} \rightarrow \mathrm{AlF}_{6}{ }^{3-}{ }_{(\mathrm{aq})}+\mathrm{Zr}^{4+}{ }_{(\mathrm{aq})}
$$

Water electrolysis:

$$
\begin{gathered}
2 \mathrm{H}^{+}{ }_{(\mathrm{aq})}+2 \mathrm{e}^{-} \rightarrow \mathrm{H}_{2(\mathrm{~g})} \\
\mathrm{H}_{2} \mathrm{O}_{(\mathrm{l})} \rightarrow \frac{1}{2} \mathrm{O}_{2(\mathrm{~g})}+2 \mathrm{H}^{+}{ }_{(\mathrm{aq})}+2 \mathrm{e}^{-}
\end{gathered}
$$

Coating deposition:

$$
\mathrm{Zr}^{4+}{ }_{(\mathrm{aq})}+4 \mathrm{H}_{2} \mathrm{O}_{(\mathrm{l})} \rightarrow \mathrm{ZrO}_{2} \cdot 2 \mathrm{H}_{2} \mathrm{O}_{(\mathrm{s})}+4 \mathrm{H}^{+}{ }_{(\mathrm{aq})}
$$

Hydrogen evolution consumes one of the products of the fourth reaction $\left(\mathrm{H}^{+}\right)$, that occurs in the cathode, therefore, this unbalances the reaction in the direction of products formation, enabling the production of more electro-assisted deposited coating (autocatalytic effect). Control over the cathodic potential applied $(-1.0 \mathrm{~V}$ instead of $-1.5 \mathrm{~V})$ regulates the hydrogen gas generation, and thus, it can be reduced to avoid the obtaining of high porous films; which in turn is not possible with DC method.

Those reactions are particularly favored in aluminum alloys where the intermetallic particles are cathodic relative to the aluminum matrix, as other authors have already observed for the application of tri-cationic phosphating pre-treatments on AA2024 alloy $[51,52]$. The abundance of such cathodic sites and the preferential deposition on their surroundings is depicted in Scheme 1a. We should mention that the representation shown in Scheme 1 is a simplification of the whole process and dissolution reactions of the native oxides and hydroxides were not shown. The key aspect regarding the role of the substrate is the presence of intermetallic particles on AA2024 surfaces (Scheme 1a), which are absent in AA1100 (Scheme 1b). The presence of intermetallics and other Cu-rich particles offers a faster deposition of $\mathrm{ZrO}_{2}$ molecules in AA2024 substrates; and it would be one of the reasons for obtaining thicker films in such samples, as explained above. In both substrates, the porosity of the native oxide/hydroxide $\mathrm{Al}$ molecules also helps $\mathrm{Zr}^{4+}$ migration to the inner interface layer. This effect is raised by the potential application, which did not occur with conversion chemical coating deposition.

In summary, both EAD and $\mathrm{DC}$ techniques enable an uniform film deposition $[19,53]$. It has been observed that, despite the $\mathrm{ZrO}_{2}$ coating formation is supposedly favored by the application of low cathodic potential in electro-assisted method, the correct mechanism is probably a combination of both a chemisorption process and the electro-assisted one happening simultaneously.

\section{6. $\mathrm{ZrO}_{2}$ Nanocoating Stability in Sodium Chloride Solution}

Finally, the $\mathrm{ZrO}_{2}$ nanocoatings, generated by DC and EAD methods, were evaluated by potentiodynamic polarization curves and EIS, after 30 min of immersion in $\mathrm{NaCl} 0.05 \mathrm{M}$ for $\mathrm{E}_{\text {ocp }}$ stabilization (Figure 8). As can be seen, AA1100 exhibits a passivation behaviour corresponding to a contribution of a pseudo-stable interface layer in all substrates, with the exception of surfaces degreased with alkaline solution. This bare sample results in more active cathodic and anodic regions due to the growth of highly higroscopic and porous compounds, like $\mathrm{AlOOH}$ or $\mathrm{Al}(\mathrm{OH})_{3}$ hydroxide compositions (Figure $8 \mathrm{a}$ ), as evidenced by XPS (Section 3.2). The measured corrosion current densities ( $\left.j_{\text {corr }}\right)$, corrosion potentials $\left(E_{\text {corr }}\right)$ and breakdown potentials $\left(E_{b}\right)$ for the AA1100 curves are shown in Table S3. All samples, with the exception of the bare one, display more positive breakdown potentials $\left(E_{b}\right)$ respect to $E_{C O R R}$. Conversely, AA2024 surfaces show the behavior of active corrosion, even though both the cathodic and the anodic polarization current densities decrease with respect to pure $\mathrm{Al}$ surfaces (Figure $8 \mathrm{~b}$ ). The less negative $\mathrm{E}_{\mathrm{corr}}$ in open circuit potential, which is observed for AA2024 samples with $\mathrm{ZrO}_{2}$ nanocoating, and the less oxigen reduction (cathodic curves) are benefitial for this substrate compared to $\mathrm{AA} 1100 / \mathrm{ZrO}_{2}$. 
Altogether allow us to conclude that $\mathrm{ZrO}_{2}$ layer is more compact on AA2024 than on AA1100, which is in accordance to the SEM and AFM results, as noted earlier.
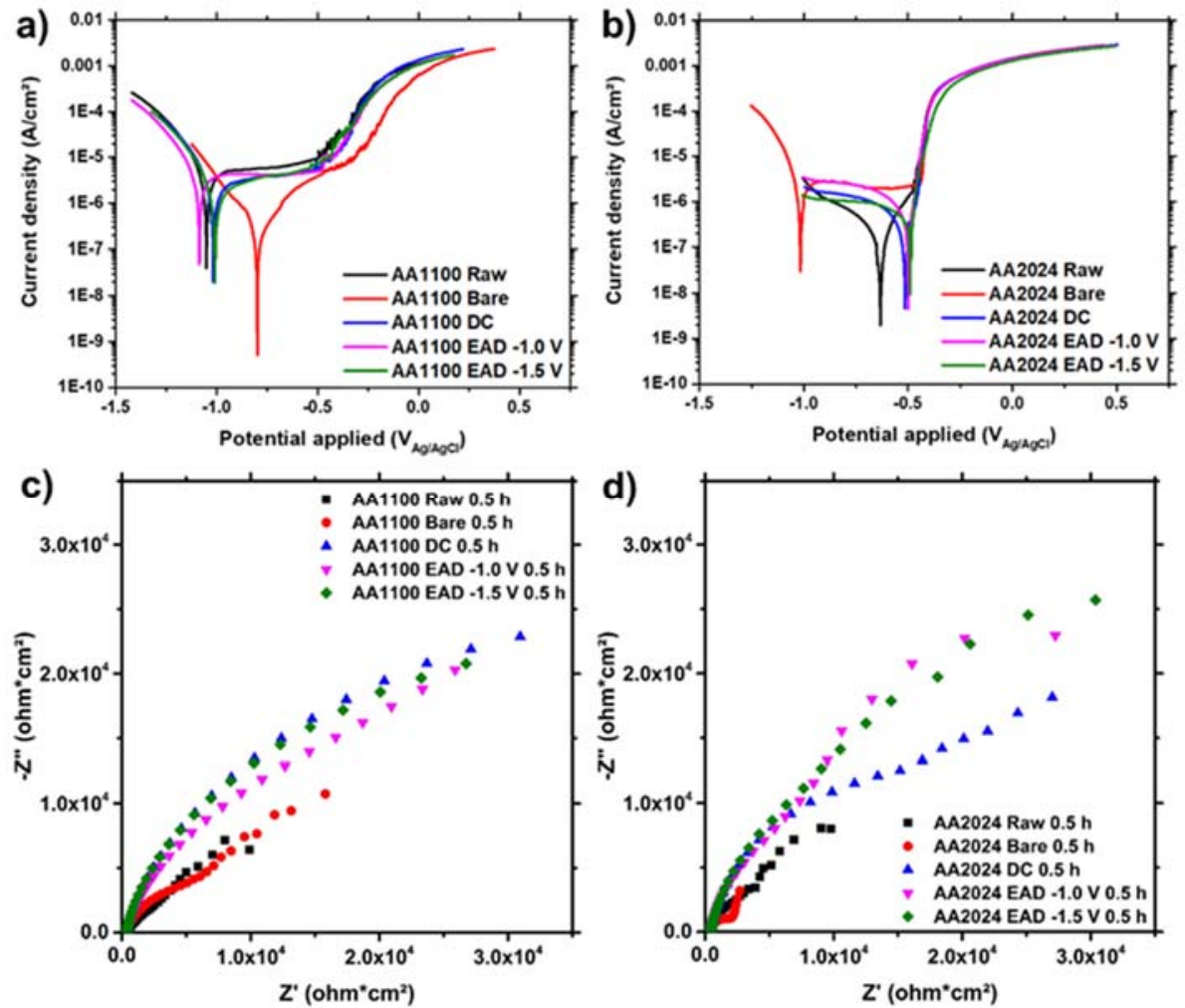

Figure 8. (a,b) Polarization curves and (c,d) Nyquist plots of AA1100 (a,c) and AA2024 (b,d) specimens after $30 \mathrm{~min}$ of immersion in aqueous $\mathrm{NaCl} 0.05 \mathrm{M}$ electrolyte.

Moreover, the AA2024 surface in bare samples (Figure $8 \mathrm{~b}$ ) probably has a positive barrier contribution of $\mathrm{CuO}, \mathrm{Cu}_{2} \mathrm{O}$ and $\mathrm{Cu}(\mathrm{OH})_{2}$ species, which are much more stable than $\mathrm{Al}$ hydroxides in similar potential and $\mathrm{pH}$ ranges (Pourbaix diagrams). However, the $\mathrm{E}_{\text {corr }}$ is too low $(-0.82 \mathrm{~V})$ and close to the standard reduction potential of pure $\mathrm{Al}(-0.76 \mathrm{~V})$. After DC and $\mathrm{EAD} \mathrm{ZrO}_{2}$ depositions, the $\mathrm{E}_{\mathrm{corr}}$ moves to positive values and $\mathrm{j}_{\text {corr }}$ values are the lowest ones $\left(10^{-7} \mathrm{~A} / \mathrm{cm}^{2}\right)$ (Table S3).

Analyzing the DC and EAD methods for the $\mathrm{ZrO}_{2}$ conversion nanocoating deposition on AA1100 and AA2024 substrates, the $\mathrm{E}_{\text {corr }}$ and the $j_{\text {corr }}$ are very similar for short exposition time. A detailed inspection of the effect of the the lowest cathodic potential $(-1.5 \mathrm{~V})$, in the coating generation compared to the highest potential $(-1.0 \mathrm{~V})$, proves that they also have similar electrochemical behaviour. Therefore, we conclude that the differences on the potential applied do not affect the barrier protection of the film, whereas it is mostly influenced by the substrate nature and the pre-treatments applied.

The presence of low content of copper is known to be beneficial for the formation of $\mathrm{Zr}$ based conversion coatings on aluminium alloys due to the difference of potential observed between the aluminium matrix and the $\mathrm{Cu}$-rich intermetallic boundaries $[25,34,54-56]$. Polarization results after DC and $\mathrm{EAD} \mathrm{ZrO}_{2}$ conversion pre-treatments in pure copper plates are discussed in the supporting information (Figure S7).

The corrosion resistance is better evaluated by measurements of polarization resistances $\left(R_{p}\right)$ by EIS surface analysis. The higher the polarization resistance (i.e., the larger the Nyquist plot diameter, Figure 8c,d), the greater the barrier effect of the coating. The highest $\mathrm{R}_{\mathrm{p}}$ values were found for substrates covered with the $\mathrm{ZrO}_{2}$ nanocoating. Table S4 indicates that the data for such samples were one order of magnitud higher than for raw and bare samples, for both AA1100 and AA2024 aluminium alloys. The resistance behaviour of $\mathrm{ZrO}_{2}$ generated by DC and EAD methods was similar on AA1100 plates (Figure 8c), whereas on 
AA2024 the first denoted the beginning of a second time constant, probably associated to a electrolyte diffusion at low frequencies (Figure 8d).

The capacitance of the double layer, measured as a constant phase element (CPE), was invariable. This is generally attributed to the surface reactivity, surface heterogeneity, and surface roughness regarding to current and potential distribution. Therefore, the Al-rich interface established in Figure 2e proves to be thin and homogenous in all samples.

These observations reinforce the understanding that the utilization of DC and EAD techniques in $\mathrm{H}_{2} \mathrm{ZrF}_{6}$ aqueous solution enables the deposition of the zirconium conversion coating in specific substrates, like those showed in this study for AA1100, AA2024 and ITO, whereas are prevented in others, like pure copper. Moreover, the electrochemical results evidence that such nanometric coatings do not represent a real protection barrier but rather a intermediate layer for further multilayer coatings depositions [27].

\section{Conclusions}

In this work, the control over the zirconium conversion nanocoating deposition on aluminum substrates was successfully achieved by the application of chemisorption ( $\mathrm{Zr}$ CCC) and electro-assisted deposition (EAD technique). The novelty of the research relies on the absence of any co-additive in the hexafluorozirconic acid aqueous solution, which represents a great advantage with respect to other bath solutions previously investigated.

The $\mathrm{ZrO}_{2}$ nanocoating generated by EAD or DC methods completely covers both the aluminum matrix and the intermetallic particles. One of the advantages of the electroassisted method is the adequate control over the deposition parameters. The presence of copper alloying elements on AA2024 surface has also been proved to play an important role, favoring the $\mathrm{ZrO}_{2}$ deposition in this aluminum alloy and showing that the EAD method occurs simultaneously with the conventional conversion reactions.

Furthermore, the deposition of the $\mathrm{Zr}$ conversion coating on conductive ITO substrates can be obtained exclusively by EAD, proving that it has potential application to be explored in other conductive substrates for which Zr-CCC is prevented.

Therefore, the results obtained in this study drive forces towards the use of $\mathrm{ZrO}_{2}$ nanocoating as an electrochemically stable layer for future primer deposition in similar multicoated systems, like that employed with phosphating processes at industry.

Supplementary Materials: The following are available online at https:/ / www.mdpi.com/1996-194 4/14/4/1043/s1, Figure S1: Elastic modulus and hardness as a function of nanoindenter penetration into sample surface: (a) Zr-EAD -1.0 V in ITO substrate; (b) Zr-EAD -1.0 V in AA1100 plates, (c) $\mathrm{Zr}-\mathrm{EAD}-1.0 \mathrm{~V}$ in AA2024. All coatings generated at $1 \mathrm{~h}$ by EAD method. Hardness is given in black filled dots and elastic modulus in empty dots; Figure S2: Cross-section high-resolution SEM images of samples after in-situ Pt deposition: (a) Zr-EAD at $-1.0 \mathrm{~V} / \mathrm{AA} 1100$, and (b) Zr-EAD at -1.0 V/AA2024. SEM magnifications: (a) 89.51 kX; (b) 86.39 kX; Figure S3: XPS survey spectra showing the main elements found in the surfaces of Raw, Bare and Zr-EAD samples, obtained with $-1.0 \mathrm{~V}$ and $-1.5 \mathrm{~V}$ in: a) AA1100 plates and b) AA2024 disks; Figure S4: $\mathrm{Cu} 2 \mathrm{p}_{1 / 2}$ (956 eV) and $\mathrm{Cu} 2 \mathrm{p}_{3 / 2}(933 \mathrm{ev})$ XPS high resolution spectra of: a) Raw, b) Bare, (c) Zr-EAD -1.0 V, and (d) Zr-EAD $-1.5 \mathrm{~V}$, detected in AA2024 disks; Figure S5: SEM micrographs evidencing the high density of $\mathrm{ZrO}_{2}$ agglomerates in AA2024 coated samples (EAD generated for $60 \mathrm{~min}$ at potentiostatic condition). The magnifications are: (a) $16 \mathrm{kX}$; (b) $38 \mathrm{kX}$; and (c) detail of the $\mathrm{ZrO}_{2}$ thick layer and the substrate at 26kX; Figure S6: AFM 3D height images of: (a) AA1100 bare sample, after raw material degreasing; (b) ZrEAD at $-1.0 \mathrm{~V} / \mathrm{AA} 1100$; (c) Zr-EAD at -1.5 V/AA1100; (d) AA2024 bare sample, after raw material degreasing; (e) Zr-EAD at -1.0 V/AA2024; (f) Zr-EAD at -1.5 V/AA2024; Figure S7: Electrochemical and visual inspection of the tested pure copper plates in presence of hexafluorozirconic acid solution: (a) photographs of the analyzed areas after polarization assays, and b) potentiodynamic polarization curves in $\mathrm{NaCl} 0.05 \mathrm{M}$ electrolyte $(0.5 \mathrm{~h})$; Table S1: Roughness of aluminum surfaces treated with degreasing agent (Bare) and electro-assisted deposition of zirconium conversion coating (EAD). The values were measured using AFM 3D topographic analyses (Figure S6) and were compared to ITO substrates; Table S2: Atomic concentration of Al 2p, Zr 3d, Cu 2p and O 1s, obtained from the XPS high resolution spectrum of each orbitals, and comparative apparent atomic ratios of main elements; 
Table S3: Corrosion potentials ( $\left.\mathrm{E}_{\mathrm{corr}}\right)$ and corrosion current densities $\left(\mathrm{j}_{\mathrm{corr}}\right)$ measured by Tafel fitting of the experimental curves obtained after samples immersion in $\mathrm{NaCl} 0.05 \mathrm{M}$ for 30 min; Table S4: Electrochemical impedance parameters for all samples, after immersion in $\mathrm{NaCl} 0.5 \mathrm{M}$ for 30 min.

Author Contributions: Conceptualization, V.B.M., A.M. and E.A.; methodology, V.B.M. and E.A.; validation, V.B.M. and E.A.; formal analysis, V.B.M., A.P.-J., E.J.-P. and E.A.; investigation, V.B.M. and E.A.; resources, C.A. and E.J.-P.; data curation, V.B.M.; writing-original draft preparation, E.A.; writing-review and editing, all authors; supervision, A.M. and E.A.; project administration, E.A.; funding acquisition, C.A. All authors have read and agreed to the published version of the manuscript.

Funding: This research was funded by MINECO, grant number RTI2018-098951-B-I00, FEDER, grant number PGC2018-096855-B-C41, and Generalitat de Catalunya, grant number 2017SGR359. V.B.M. received funding from Conselho Nacional de Desenvolvimento Científico e Tecnológico, grant numbers n ${ }^{\circ}$ 200890/2018-2 and 142042/2017-0, and Coordenação de Aperfeiçoamento de Pessoal de Nível Superior, grant number 88881.188990/2018-01.

Institutional Review Board Statement: Not applicable.

Informed Consent Statement: Not applicable.

Data Availability Statement: The data presented in this study are available in the main text and supplementary file or upon request to the corresponding author.

Acknowledgments: We would like to acknowledge Trifon Trifonov for his help with high resolution SEM images and Montserrat Domínguez and Jordi Sans for their help with XPS analysis.

Conflicts of Interest: The authors declare no conflict of interest.

\section{References}

1. Streitberger, H.-J.; Goldschmidt, A. BASF Handbook Basics of Coating Technology, 3rd ed.; Streitberger, H.-J., Goldschmidt, A., Eds.; European Coatings: Munster, Germany, 2018.

2. Schütze, M.; Wieser, D.; Bender, B. Corrosion Resistance of Aluminium and Aluminium Alloys; Schütze, M., Wieser, D., Bender, B., Eds.; John Wiley \& Sons, Ltd.: Frankfurt, Germany, 2010.

3. Narayanan, T.S.N.S. Surface pretreatment by phosphate conversion coatings-A review. Rev. Adv. Mater. Sci. $2005,9,130-177$.

4. Freeman, D.B. Phosphating and Metal Pre-Treatment: A Guide to Modern Processes and Practice; Freeman, D.B., Ed.; Industrial Press: Michigan, USA, 1986; ISBN 0831111682.

5. Martínez-Viademonte, M.P.; Abrahami, S.T.; Hack, T.; Burchardt, M.; Terryn, H. A review on anodizing of aerospace aluminum alloys for corrosion protection. Coatings 2020, 10, 1106. [CrossRef]

6. Sander, J.; Kirmaier, L.; Manea, M.; Shchukin, D.; Skorb, E. Anticorrosive Coatings: Fundamentals and New Concepts; Sander, J., Kirmaier, L., Manea, M., Shchukin, D., Skorb, E., Eds.; Vincentz Network: Hanover, Germany, 2010; ISBN 9783866309111.

7. Nicole, L.; Laberty-Robert, C.; Rozes, L.; Sanchez, C. Hybrid materials science: A promised land for the integrative design of multifunctional materials. Nanoscale 2014, 6, 6267-6292. [CrossRef]

8. Kim, M.M.; Kapun, B.; Tiringer, U.; Šekularac, G.; Milošev, I. Protection of aluminum alloy 3003 in sodium chloride and simulated acid rain solutions by commercial conversion coatings containing Zr and Cr. Coatings 2019, 9, 563. [CrossRef]

9. Milošev, I.; Frankel, G.S. Conversion Coatings Based on Zirconium and/or Titanium. J. Electrochem. Soc. 2018, 165, C127-C144. [CrossRef]

10. Zhang, H.; Zhang, X.; Zhao, X.; Tang, Y.; Zuo, Y. Preparation of Ti-Zr-based conversion coating on 5052 aluminum alloy, and its corrosion resistance and antifouling performance. Coatings 2018, 8, 397. [CrossRef]

11. Eivaz Mohammadloo, H.; Sarabi, A.A.; Asemani, H.R.; Ahmadi, P. A comparative study of eco-friendly hybrid thin films: With and without organic coating application. Prog. Org. Coat. 2018, 125, 432-442. [CrossRef]

12. Cardoso, H.R.P.; Rapacki, C.; Ferreira, J.Z. Monitoring of a Zr-based conversion coating on galvanised steel and its performance against corrosion. Corros. Eng. Sci. Technol. 2019, 54, 726-730. [CrossRef]

13. Liu, X.; Vonk, D.; Jiang, H.; Kisslinger, K.; Tong, X.; Ge, M.; Nazaretski, E.; Ravel, B.; Foster, K.; Petrash, S.; et al. Environmentally Friendly Zr-Based Conversion Nanocoatings for Corrosion Inhibition of Metal Surfaces Evaluated by Multimodal X-ray Analysis. ACS Appl. Nano Mater. 2019, 2, 1920-1929. [CrossRef]

14. Han, J.; Thierry, D.; Ogle, K. Zr-based conversion coating on Zn and Zn-Al-Mg alloy coating: Understanding the accelerating effect of $\mathrm{Cu}$ (II) and $\mathrm{NO}^{3-}$. Surf. Coat. Technol. 2020, 402, 126236. [CrossRef]

15. Ogle, K.; Buchheit, R.G. Conversion Coatings. Encyclopedia of Electrochemistry; Wiley-VCH GmbH \& Co. KGaA: Weinheim, Germany, 2007; pp. 460-499.

16. Ramanathan, E.; Balasubramanian, S. Comparative study on polyester epoxy powder coat and amide cured epoxy liquid paint over nano-zirconia treated mild steel. Prog. Org. Coat. 2016, 93, 68-76. [CrossRef] 
17. Cerezo, J.; Vandendael, I.; Posner, R.; Lill, K.; de Wit, J.H.W.; Mol, J.M.C.; Terryn, H. Initiation and growth of modified Zr-based conversion coatings on multi-metal surfaces. Surf. Coat. Technol. 2013, 236, 284-289. [CrossRef]

18. Giacomelli, F.C.; Giacomelli, C.; De Oliveira, A.G.; Spinelli, A. Effect of electrolytic $\mathrm{ZrO}_{2}$ coatings on the breakdown potential of NiTi wires used as endovascular implants. Mater. Lett. 2005, 59, 754-758. [CrossRef]

19. Dong, X.; Argekar, S.; Wang, P.; Schaefer, D.W. In situ Evolution of Trivalent Chromium Process Passive Film on Al in a Corrosive Aqueous Environment. ACS Appl. Mater. Interfaces 2011, 3, 4206-4214. [CrossRef]

20. Moreira, V.B.; Ferreira, J.Z.; Meneguzzi, A. Pré-tratamento por deposição eletroassistida de viniltrietoxissilano (VTES) para a pintura de alumínio. Tecnol. Metal. Mater. Mineração 2018, 15, 68-74. [CrossRef]

21. Moreira, V.B.; Cardoso, H.R.P.; Ferreira, J.Z.; Meneguzzi, Á. DEPOSIÇÃO ELETROASSISTIDA DE ORTOSSILICATO DE TETRAETILA (TEOS) COMO PRÉ-TRATAMENTO PARA A PINTURA DE ALUMÍNIO AA1100. Tecnol. Metal. Mater. Mineração 2018, 15, 56-62. [CrossRef]

22. Li, L.; Swain, G.M. Effects of Aging Temperature and Time on the Corrosion Protection Provided by Trivalent Chromium Process Coatings on AA2024-T3. ACS Appl. Mater. Interfaces 2013, 5, 7923-7930. [CrossRef] [PubMed]

23. Oliver, W.C.; Pharr, G.M. Measurement of hardness and elastic modulus by instrumented indentation: Advances in understanding and refinements to methodology. J. Mater. Res. 2004, 19, 3-20. [CrossRef]

24. Roa, J.J.; Jiménez-Piqué, E.; Anglada, M.J. Nanoindentation of Advanced Ceramics: Applications to ZrO2 Materials. In Applied Nanoindentation in Advanced Materials; Tiwari, A., Natarajan, S., Eds.; John Wiley \& Sons, Ltd.: Hoboken, NJ, USA, 2017; pp. 459-480. ISBN 1119084490.

25. Sarfraz, A.; Posner, R.; Lange, M.M.; Lill, K.; Erbe, A. Role of Intermetallics and Copper in the Deposition of ZrO 2 Conversion Coatings on AA6014. J. Electrochem. Soc. 2014, 161, C509-C516. [CrossRef]

26. Gusmano, G.; Montesperelli, G.; Rapone, M.; Padeletti, G.; Cusmà, A.; Kaciulis, S.; Mezzi, A.; Maggio, R. Di Zirconia primers for corrosion resistant coatings. Surf. Coat. Technol. 2007, 201, 5822-5828. [CrossRef]

27. Andreatta, F.; Paussa, L.; Lanzutti, A.; Rosero Navarro, N.C.; Aparicio, M.; Castro, Y.; Duran, A.; Ondratschek, D.; Fedrizzi, L. Development and industrial scale-up of $\mathrm{ZrO}_{2}$ coatings and hybrid organic-inorganic coatings used as pre-treatments before painting aluminium alloys. Prog. Org. Coat. 2011, 72, 3-14. [CrossRef]

28. Gaillard, Y.; Anglada, M.; Jiménez-Piqué, E. Nanoindentation of yttria-doped zirconia: Effect of crystallographic structure on deformation mechanisms. J. Mater. Res. 2009, 24, 719-727. [CrossRef]

29. Jiménez-Piqué, E.; González-García, L.; Rico, V.J.; González-Elipe, A.R. Nanoindentation of nanocolumnar TiO 2 thin films with single and stacked zig-zag layers. Thin Solid Film. 2014, 550, 444-449. [CrossRef]

30. Gaillard, Y.; Rico, V.J.; Jiménez-Piqué, E.; González-Elipe, A.R. Nanoindentation of $\mathrm{TiO}_{2}$ thin films with different microstructures. J. Phys. D Appl. Phys. 2009, 42, 145305. [CrossRef]

31. Kassavetis, S.; Logothetidis, S.; Zyganitidis, I. Nanomechanical testing of the barrier thin film adhesion to a flexible polymer substrate. J. Adhes. Sci. Technol. 2012, 26, 2393-2404. [CrossRef]

32. Fockaert, L.I.; Taheri, P.; Abrahami, S.T.; Boelen, B.; Terryn, H.; Mol, J.M.C. Zirconium-based conversion film formation on zinc, aluminium and magnesium oxides and their interactions with functionalized molecules. Appl. Surf. Sci. 2017, 423, 817-828. [CrossRef]

33. Šekularac, G.; Kovač, J.; Milošev, I. Comparison of the Electrochemical Behaviour and Self-sealing of Zirconium Conversion Coatings Applied on Aluminium Alloys of series 1xxx to 7xxx. J. Electrochem. Soc. 2020, 167, 111506. [CrossRef]

34. George, F.O.; Skeldon, P.; Thompson, G.E. Formation of zirconium-based conversion coatings on aluminium and Al-Cu alloys. Corros. Sci. 2012, 65, 231-237. [CrossRef]

35. Cerezo, J.; Vandendael, I.; Posner, R.; de Wit, J.H.W.; Mol, J.M.C.; Terryn, H. The effect of surface pre-conditioning treatments on the local composition of Zr-based conversion coatings formed on aluminium alloys. Appl. Surf. Sci. 2016, 366, 339-347. [CrossRef]

36. Torras, J.; Azambuja, D.S.; Wolf, J.M.; Alemán, C.; Armelin, E. How organophosphonic acid promotes silane deposition onto aluminum surface: A detailed investigation on adsorption mechanism. J. Phys. Chem. C 2014, 118, 17724-17736. [CrossRef]

37. Cerezo, J.; Taheri, P.; Vandendael, I.; Posner, R.; Lill, K.; de Wit, J.H.W.; Mol, J.M.C.; Terryn, H. Influence of surface hydroxyls on the formation of Zr-based conversion coatings on AA6014 aluminum alloy. Surf. Coat. Technol. 2014, 254, 277-283. [CrossRef]

38. Buchheit, R.G.; Martinez, M.A.; Montes, L.P. Evidence for $\mathrm{Cu}$ Ion Formation by Dissolution and Dealloying the Al2CuMg Intermetallic Compound in Rotating Ring-Disk Collection Experiments. J. Electrochem. Soc. 2000, 147, 119. [CrossRef]

39. Vukmirovic, M.B.; Dimitrov, N.; Sieradzki, K. Dealloying and Corrosion of Al Alloy 2024-T3. J. Electrochem. Soc. 2002, 149 , B428. [CrossRef]

40. Hashimoto, T.; Zhang, X.; Zhou, X.; Skeldon, P.; Haigh, S.J.; Thompson, G.E. Investigation of dealloying of S phase (Al2CuMg) in AA 2024-T3 aluminium alloy using high resolution 2D and 3D electron imaging. Corros. Sci. 2016, 103, 157-164. [CrossRef]

41. Zhang, X.; Hashimoto, T.; Lindsay, J.; Zhou, X. Investigation of the de-alloying behaviour of $\theta$-phase (A12Cu) in AA2024-T351 aluminium alloy. Corros. Sci. 2016, 108, 85-93. [CrossRef]

42. Šekularac, G.; Kovač, J.; Milošev, I. Prolonged protection, by zirconium conversion coatings, of AlSi7Mg0.3 aluminium alloy in chloride solution. Corros. Sci. 2020, 169, 108615. [CrossRef]

43. Lostak, T.; Krebs, S.; Maljusch, A.; Gothe, T.; Giza, M.; Kimpel, M.; Flock, J.; Schulz, S. Formation and characterization of Fe3+-/Cu2+-modified zirconium oxide conversion layers on zinc alloy coated steel sheets. Electrochim. Acta 2013, 112, 14-23. [CrossRef] 
44. Yen, S.; Guo, M.; Zan, H. Characterization of electrolytic $\mathrm{ZrO}_{2}$ coating on Co-Cr-Mo implant alloys of hip prosthesis. Biomaterials 2001, 22, 125-133. [CrossRef]

45. Eivaz Mohammadloo, H.; Sarabi, A.A.; Sabbagh Alvani, A.A.; Sameie, H.; Salimi, R. Nano-ceramic hexafluorozirconic acid based conversion thin film: Surface characterization and electrochemical study. Surf. Coat. Technol. 2012, 206, 4132-4139. [CrossRef]

46. Zhang, F.; Jacobi, A.M. Aluminum surface wettability changes by pool boiling of nanofluids. Colloids Surf. Physicochem. Eng. Asp. 2016, 506, 438-444. [CrossRef]

47. Gonzalez-Canche, N.G.; Flores-Johnson, E.A.; Cortes, P.; Carrillo, J.G. Evaluation of surface treatments on 5052-H32 aluminum alloy for enhancing the interfacial adhesion of thermoplastic-based fiber metal laminates. Int. J. Adhes. Adhes. 2018, 82, 90-99. [CrossRef]

48. Mrad, M.; Ben Amor, Y.; Dhouibi, L.; Montemor, M.F. Effect of AA2024-T3 surface pretreatment on the physicochemical properties and the anticorrosion performance of $\operatorname{poly}(\gamma$-glycidoxypropyltrimethoxysilane) sol-gel coating. Surf. Interface Anal. 2018, 50, 335-345. [CrossRef]

49. Doerre, M.; Hibbitts, L.; Patrick, G.; Akafuah, N. Advances in Automotive Conversion Coatings during Pretreatment of the Body Structure: A Review. Coatings 2018, 8, 405. [CrossRef]

50. Li, L.; Desouza, A.L.; Swain, G.M. In situ pH measurement during the formation of conversion coatings on an aluminum alloy (AA2024). Analyst 2013, 138, 4398. [CrossRef] [PubMed]

51. Parvizi, R.; Marceau, R.K.W.; Hughes, A.E.; Tan, M.Y.; Forsyth, M. Atom probe tomography study of the nanoscale heterostructure around an Al20Mn3Cu2 dispersoid in aluminum alloy 2024. Langmuir 2014, 30, 14817-14823. [CrossRef]

52. Li, L.; Whitman, B.W.; Swain, G.M. Characterization and Performance of a Zr/Ti Pretreatment Conversion Coating on AA2024-T3. J. Electrochem. Soc. 2015, 162, C279-C284. [CrossRef]

53. Shruthi, T.K.; Swain, G.M. Communication-Role of Trivalent Chromium on the Anti-Corrosion Properties of a TCP Conversion Coating on Aluminum Alloy 2024-T3. J. Electrochem. Soc. 2018, 165, C103-C105. [CrossRef]

54. Dong, X.; Wang, P.; Argekar, S.; Schaefer, D.W. Structure and Composition of Trivalent Chromium Process (TCP) Films on Al Alloy. Langmuir 2010, 26, 10833-10841. [CrossRef] [PubMed]

55. Adhikari, S.; Unocic, K.A.; Zhai, Y.; Frankel, G.S.; Zimmerman, J.; Fristad, W. Hexafluorozirconic acid based surface pretreatments: Characterization and performance assessment. Electrochim. Acta 2011, 56, 1912-1924. [CrossRef]

56. Van Ingelgem, Y.; Hubin, A.; Vereecken, J. Investigation of the first stages of the localized corrosion of pure copper combining EIS, FE-SEM and FE-AES. Electrochim. Acta 2007, 52, 7642-7650. [CrossRef] 